Family Medicine and Community Health

\section{Comparison of self-report and objective measures of male sexual dysfunction in a Japanese primary care setting: a cross- sectional, self-administered mixed methods survey}

\author{
Yuki Takeuchi (D) , ${ }^{1}$ Ryohei Otsuka, ${ }^{1}$ Hajime Kojima, ${ }^{1}$ Michael D Fetters ${ }^{2}$
}

To cite: Takeuchi Y, Otsuka R, Kojima $\mathrm{H}$, et al. Comparison of self-report and objective measures of male sexual dysfunction in a Japanese primary care setting: a crosssectional, self-administered mixed methods survey. Fam Med Com Health 2021;9:e000403. doi:10.1136/ fmch-2020-000403

- Additional material is published online only. To view please visit the journal online (http://dx.doi.org/10.1136/fmch2020-000403).
Check for updates

(C) Author(s) (or their employer(s)) 2021. Re-use permitted under CC BY-NC. No commercial re-use. See rights and permissions. Published by BMJ.

${ }^{1}$ Teine Family Medicine Clinic, Teine Keijinkai Hospital, Sapporo, Hokkaido, Japan ${ }^{2}$ Mixed Methods Program, Department of Family Medicine, University of Michigan, Ann Arbor, Michigan, USA

Correspondence to Dr Yuki Takeuchi; ytakeuchi1016@gmail.com

\section{ABSTRACT}

Objectives Erectile dysfunction (ED) is a common problem among middle-aged males and men often do not talk about sexual problems with their primary care physicians (PCPs). We hypothesised that many Japanese men who meet the criteria for ED would not recognise their condition based on responses to an internationally validated scale. Our secondary aims were to examine potential barriers to seeking treatment for ED by their PCPs. We sought to elucidate their perspectives about male sexual dysfunction qualitatively. Through merging of the quantitative and qualitative findings, we sought an enhanced understanding of the factors affecting sexual dysfunction treatment. Design A cross-sectional, self-administered mixed methods survey was distributed at a suburban family medicine clinic in Sapporo, Japan. Eligible participants were 40 to 69-year-old men who came for routine scheduled visits from 5 November to 21 December 2018. During the office visit, participants completed a confidential 11-item survey addressing sexual dysfunction including the 5-item version of the International Index of Erectile Function scale and openended questioning.

Setting Teine Family Medicine Clinic, a suburban family medicine clinic in Sapporo, Japan.

Participants We enroled 66 male patients aged 40-69 years who presented for routine outpatient care in the Teine Family Medicine Clinic.

Results Of surveyed participants, 39\% (26/66) reported having sexual dysfunction, but $92 \%$ (61/66) met ED criteria. Of respondents, 48\% (16/33) had desire for treatment, but only one man had discussed sexual dysfunction with his PCP. Among the 12 desiring treatment from PCPs, the main barriers to discussing were shame $(n=7)$ and lack of awareness that PCPs can treat ED $(n=5)$. These men's perspectives about sexual dysfunction included viewing sexual dysfunction as normal ageing, attributing sexual dysfunction to decreased libido, considering sexual activity for a healthy life, having good rapport with PCPs, having incomplete knowledge about treatment and lacking an intimate relationship. Through a resulting model, the merged mixed methods findings illustrate how patient perceptions can reinforce or attenuate issues of awareness, desire for treatment and barriers to access.

Conclusions In a Japanese primary care setting, the majority of participating male patients met ED criteria on

\section{Key points}

\section{Question}

- Erectile dysfunction (ED) is an important aspect of male sexual health and a common and treatable condition among middle-aged males. We hypothesised that many Japanese men who met criteria for ED would not recognise their condition. We their merged their reports about barriers to treatment with their perspectives on treatment to better understand factors affecting sexual dysfunction treatment.

\section{Findings}

- Of surveyed participants, 39\% (26/66) reported having sexual dysfunction, but $92 \%(61 / 66)$ met $E D$ criteria. A model based on the mixed methods findings illustrates how patient perceptions reinforce or attenuate awareness, desire for treatment and barriers to access.

\section{Meaning}

- Lack of awareness, misperceptions and attitudinal barriers inhibit middle-aged males from discussing sexual health. PCPs should routinely inquire about sexual dysfunction to enhance recognition if underlying ED is present, and elucidate men's perceptions about their condition and preferences for medical treatment.

an internationally validated measure, namely, the five-item version of the International Index of Erectile Function, but many were not aware of their ED. Misperceptions, lack of knowledge and personal factors are barriers to treatment. The mixed methods findings suggest misperceptions and personal attributes reinforce or attenuate awareness, preference for treatment and barriers to access. We conclude PCPs should routinely inquire about sexual dysfunction of men at risk and offer treatment to men who would benefit.

\section{INTRODUCTION}

Male sexual dysfunction is defined as a clinically significant disturbance in a man's ability to respond sexually or to experience 
sexual pleasure. ${ }^{1}$ Erectile dysfunction (ED) is the most common problem of male sexual dysfunction and considered primarily a problem of men older than 40 years of age. ${ }^{2}$ Data from the 2015-2016 Nation Health and Wellness Survey provide estimates of the global prevalence of ED in men aged $40-70$ years old-overall $45.2 \%$ : Italy $(52.5 \%)$, France $(47.8 \%)$, China $(47.4 \%)$, Spain $(46.6 \%)$, Germany $(46.1 \%)$, US (46,1\%), UK (42.6\%) and Brazil $(42.1 \%){ }^{3}$ A meta-analysis estimates that the prevalence of ED in Asia (Japan, Korea, China, Singapore) is $41.5 \%$ in men aged $40-49,61.8 \%$ in men aged $50-59$ and $69.6 \%$ in men aged $60-69 .{ }^{4}$ In Japan, the reported prevalence of ED among at-risk age groups to be $63.7 \%$ in men aged $40-49$ years, $78.2 \%$ in men aged $50-59$ years and $90.3 \%$ in men aged 60-69 years. ${ }^{4} \mathrm{ED}$ is a common condition in the primary care setting and negatively affects quality of life (QOL) ${ }^{56}$

Historically, treatment of sexual dysfunction was primarily psychosocial until the development of testosterone replacement in $1970 \mathrm{~s} .{ }^{7}$ Unfortunately, testosterone injections and patch formulations both have high rates of side effects, and compliance is difficult, ${ }^{8}$ particularly with injected testosterone. Moreover, the Food and Drug Administration in the USA considers testosterone to be a controlled substance which poses a significant barrier to access. ${ }^{9}$ In Japan, only testosterone injection is available, but testosterone replacement therapy is approved only for hypogonadism treatment. ${ }^{10}$

The advent of phosphodiesterase type 5 (PDE5) inhibitors created a new opportunity for treatment of ED. PDE5 inhibitors work by inhibiting guanosine 3',5'-cyclic monophosphate (cGMP) hydrolysis. The accumulation of cGMP leads to smooth-muscle relaxation in the corpus cavernosum and increased blood flow to the penis. Thus, an increase in cGMP in smooth muscle cells is responsible for prolonging an erection. ${ }^{11}$ Four types of oral PDE5 inhibitors are available in the USA. In Japan, only sildenafil, vardenafil and tadalafil are available, and these three agents can be prescribed by any physician with a medical license including primary care physicians (PCPs). By extrapolating from the 2001-2002 National Health and Nutrition Examination Survey, it has been estimated that the cost associated with treatment of ED would be US $\$ 15$ billion in the USA if all men affected with ED were to seek treatment. ${ }^{12}$ However, global sales of PDE5 inhibitors were US $\$ 4.82$ billion in $2017,{ }^{13}$ suggesting that many men afflicted with ED may be untreated. While not suggesting that all men should be treated for ED, this gap suggests that there may be many men who would benefit from treatment for ED as a component of an overall treatment strategy.

Even though ED occurs commonly and effective treatment is available, many patients do not seek treatment for sexual dysfunction. ${ }^{14-17}$ Previous international research on barriers to seeking treatment showed many patients were concerned there would be no treatment and doctors would dismiss their complaints. ${ }^{18}$ Compared with men in western countries, men in East Asia (China, Hong Kong,
Taiwan, South Korea and Japan) were the least likely to take any action. ${ }^{14} 1517$ In one study, lack of perception of a problem and the belief that sexual dysfunction is not a medical issue were the most frequent reasons cited for not seeking medical help among East Asian men. ${ }^{17}$ Embarrassment about having a sexual problem has also been found as a main reason in East Asian countries. ${ }^{17}$ Qualitative research in China showed patients perceived sexual dysfunction as embarrassing and potentially shameful, and that men preferred consultation with same gender and age PCPs. ${ }^{19}$ A previous study in Korea showed only $2 \%$ of people with sexual dysfunction had talked to a medical doctor about their sexual problems due to believing that the problem is not serious, not being bothered by the problem, not having access to medical care and lacking of awareness of available treatments. ${ }^{20}$ A previous study conducted in Japan with PCPs identified the perception that the act of seeking sexual dysfunction treatment may be intensely embarrassing for Japanese men. ${ }^{21}$

While many men may perceive that sexual dysfunction falls primarily in the scope of care of urologists, PCPs far outnumber urologists and are positioned to provide PDE5 inhibitor therapy for men desiring ED treatment. Previous research in China suggests patients view PCPs as the most appropriate professional with whom to discuss sexual problems. ${ }^{19}$ However, Nicolosi et al estimated about $90 \%$ of East Asian people with some degree of sexual dysfunction had never talked about the problem with their PCPs. ${ }^{17}$ As treatment could enhance the QOL of men with ED, PCPs need to better understand patient's perspectives on sexual dysfunction.

Previous research conducted in East Asia showed lack of perception of sexual problems and belief that sexual dysfunction is not a medical issue as main reasons for not seeking medical help. ${ }^{17}$ We hypothesised Japanese patients may not recognise their sexual dysfunction as a medical problem. Our secondary aims were to examine factors that would be barriers to consulting for treatment and gain a greater understanding qualitatively of participants' perspectives on sexual dysfunction. Our mixed methods purpose was to integrate the quantitative and qualitative results by merging attitudinal factors with the qualitative perspectives.

The purposes of this research were (1) to examine at-risk Japanese men's awareness of ED by comparing a single item self-perception assessment of sexual dysfunction with a five-item objective measure of $\mathrm{ED}$, to assess their desire for treatment, and to gauge attitudes about treatment by PCPs, (2) to qualitatively elucidate participating men's perspectives about their preferences for sexual dysfunction treatment based on written comments and (3) to merge both types of findings to gain an enhanced understanding of how the men's awareness of ED, desire for treatment and barriers to access linked with their perspectives about ED using joint display analysis and development of a model. 


\section{METHODS}

\section{Study design}

We conducted a cross-sectional, self-administered mixed methods paper survey ${ }^{22}$ in a 7 -week period from 5 November to 21 December 2018, and conducted a chart review of enroled patients to collect their demographic and health information. Our research paradigm was based on pragmatism as we sought a practical and feasible approach requiring both quantitative and qualitative data collection. ${ }^{23}$ This study was approved by a research ethics committee of Teine Keijinkai Hospital (ID 2018-166). All participants provided written informed consent for this study.

\section{Setting}

A suburban family medicine residency training programme clinic in Sapporo on the northern Island of Japan served as the research setting. This clinic is similar to many other primary care clinics in Japan, as the physicians deliver full-range primary care to the local population. Established in 2009, the clinic has 14 physicians, including 7 attendings, and 7 residents. The gender of physicians are 10 men and 4 women. The clinic provides a full range of primary care services including women's healthcare, and care to patients with a wide spectrum of ages spanning from children in the first year of life to old-old adults with the eldest patient's age in the practice currently at 103 years. The percentage of male patients in the age range of men at risk for $\mathrm{ED}$ is similar to the general population.

\section{Participants}

We used criterion sampling. The target population was middle-aged men presenting in a primary care setting for a health check-up. These criteria were chosen because middle-aged men who were in the age range of 40-69 are at high risk for ED. ${ }^{24}$ Moreover, the results should reflect a setting informative for family doctors and other PCPs. Finally, the health check-up visit type was chosen as an encounter explicitly framed for optimising health. Of eligible participants, 464 patients came into the clinic for routine check-ups during clinic operations. The questionnaire was distributed to 78 men and 70 returned the instrument for a response rate of $90 \%$. Four participants who did not answer the survey questions fully were deemed non-eligible resulting in a sample size of 66 men (full participation rate of $85 \%, 66 / 78)$. Patients deposited completed questionnaires into a secure collection box in the lobby. Qualitative comments were recorded by $32 \%(21 / 66)$ of participants.

\section{Data collection tools}

The 11-item survey comprised two sections (see online supplemental appendix). Section A of the questionnaire addressed self-reported sexual dysfunction (one question), desire for treatment and open response for rationale (two questions), attitudes about treatment of sexual dysfunction by PCPs (3 questions, total of 9 items). Section B was the Japanese IIEF-5, a fiveitem multidimensional, self-administered questionnaire developed in Japan for screening and classifying severity of ED. ${ }^{25}$ Based on data collection with 1152 men (1036 with ED, 116 control), the validated IIEF-5 has been shown to have $98 \%$ sensitivity and $88 \%$ specificity. ${ }^{26}$ The Japanese IIEF-5 is a translation of this validated tool. ${ }^{25}$ The cut-off score is less than 22 points. ED severity is defined as follows: $17-21$ points is mild; $12-16$ points is mild-to-moderate; $8-11$ points is moderate; and less than 8 points is severe. ${ }^{26}$ The chart abstraction protocol involved using the participant unique patient ID number and the recording of marital status, current and past medical history and social history as documented in the most recent regular check-up in the chart of participants.

\section{Data collection and entry procedures}

PCPs distributed the confidential survey to eligible patients at the end of their routine primary health check visits. PCPs recorded and linked in a tracking sheet the distributed questionnaire's identification number with the receiving participants' electronic chart unique identifier at each visit. A research assistant abstracted the patients' medical information from their electronic charts by using the tracking sheet with the corresponding list of questionnaire identification numbers and electronic chart unique identifiers.

\section{Data analysis}

We calculated descriptive statistics on the quantitative data with the software Easy R (EZR V.1.37). Results of the IIEF-5 were expressed in terms of the severity and distribution among the subjects. We calculated the SD for the IIEF-5 scores, 95\% CI for question answer rates and performed Mann-Whitney U test and Kruskal-Wallis test for IIEF-5 score comparison between each group. The logic of merging the qualitative and quantitative data was to obtain an enhanced understanding of both the survey and qualitative findings, ${ }^{27}$ specifically to examine how patient perspectives reinforced or attenuated the three primary study domains of awareness, desire for treatment and barriers to access. We identified codes for organising the qualitative comments by looking for emerging themes using a template approach. ${ }^{28}$ This involved an immersion/crystallisation process which involves multiple readings of the qualitative text, and development of a coding scheme reflecting the major constructs identified. ${ }^{29}$ The mixed methods integration involved development of a model as a mixed methods joint display figure ${ }^{30}$ that merged the mixed data findings. Specifically, we examined directionality of influence, reinforcement or attenuation, of the qualitative findings when linked with the three key quantitative constructs of the survey, awareness, desire for treatment and barriers to treatment. We assessed the 'fit', that is, an interpretation of the two types of findings to look 
Table 1 Characteristics of 66 participants

\begin{tabular}{|c|c|c|c|c|c|c|c|c|}
\hline \multirow[b]{4}{*}{ Characteristics } & \multicolumn{8}{|c|}{ Age group, years } \\
\hline & \multirow{2}{*}{\multicolumn{2}{|c|}{$\begin{array}{l}40-49 \\
n=10\end{array}$}} & \multirow{2}{*}{\multicolumn{2}{|c|}{$\begin{array}{l}50-59 \\
n=18\end{array}$}} & \multirow{2}{*}{\multicolumn{2}{|c|}{$\begin{array}{l}60-69 \\
n=38\end{array}$}} & \multirow{2}{*}{\multicolumn{2}{|c|}{$\begin{array}{l}\text { All age } \\
\text { groups }\end{array}$}} \\
\hline & & & & & & & & \\
\hline & $\mathbf{n}$ & $\%$ & $\mathbf{n}$ & $\%$ & $\mathrm{n}$ & $\%$ & $\mathbf{n}$ & $\%$ \\
\hline Married & 5 & 50 & 11 & 61 & 31 & 82 & 47 & 71 \\
\hline \multicolumn{9}{|l|}{ Past or present medical condition } \\
\hline Hypertension & 6 & 60 & 14 & 78 & 33 & 87 & 53 & 80 \\
\hline Dyslipidaemia & 3 & 30 & 8 & 44 & 17 & 45 & 28 & 42 \\
\hline Diabetes & 3 & 30 & 7 & 39 & 12 & 32 & 22 & 33 \\
\hline Diabetic neuropathy & 0 & 0 & 0 & 0 & 2 & 5 & 2 & 3 \\
\hline Peripheral vascular disease & 0 & 0 & 0 & 0 & 1 & 3 & 1 & 2 \\
\hline Depression & 0 & 0 & 0 & 0 & 1 & 3 & 1 & 2 \\
\hline Prostate surgery & 0 & 0 & 0 & 0 & 1 & 3 & 1 & 2 \\
\hline \multicolumn{9}{|l|}{ Smoking status } \\
\hline Current smoker & 3 & 30 & 8 & 44 & 6 & 16 & 17 & 26 \\
\hline Past smoker & 5 & 50 & 5 & 28 & 26 & 68 & 36 & 55 \\
\hline Habitual drinker (>2 drinks/day) & 0 & 0 & 4 & 22 & 9 & 24 & 13 & 20 \\
\hline \multicolumn{9}{|l|}{ Medication used } \\
\hline Antihypertensives & 4 & 40 & 14 & 78 & 26 & 68 & 44 & 67 \\
\hline
\end{tabular}

*Lifestyle diseases include hypertension, diabetes and dyslipidaemia.

for convergence, complementarity, expansion or divergence and metainferences to be drawn based on the results. ${ }^{31} 32$

\section{RESULTS}

\section{Participants}

Table 1 shows the characteristics of the subjects. As 66 men completed the surveys, and there are 464 men of this age in the clinic, the sample represents about $14 \%$ of eligible male patients. As shown, the mean age of participants was 60 years old. Demographic data suggest $98 \%(65 / 66)$ of participants had some lifestyle diseases (hypertension, diabetes or dyslipidaemia) and the most common problem was hypertension $(80 \%, 53 / 66)$.

\section{Awareness of sexual dysfunction}

Comparison of self-perceived sexual dysfunction and validated measure of ED

Among the respondents, 39\% (26/66) self-reported having sexual dysfunction (table 2). Of the 66 participants, 92\% (61/66) met ED criteria of the IIEF-5: mild $(n=27)$, mild-to-moderate $(n=15)$, moderate $(n=7)$ or severe $(n=12)$. The severe ED group includes four sexually inactive participants. Figure 1 shows the distribution of self-reported sexual dysfunction and ED according to the IIEF-5 score.

International Index of Erectile Function-5 scores in each group Table 3 displays the mean IIEF-5 scores in each group. IIEF-5 scores in the 60-69 year-old group were significantly

Table 2 'Yes' answer rates of Q1-Q2 among all participants

\begin{tabular}{lllll}
\hline & \multicolumn{3}{l}{ 'Yesponses } & \multicolumn{2}{l}{ 'Yes' answers } \\
\cline { 2 - 5 } & $\mathbf{N}$ & $\mathbf{n}$ & $\%$ & $\mathbf{9 5 \%} \mathbf{C l}$ \\
\hline Do you have any sexual dysfunction? & 66 & 26 & 39.3 & $27.6 \%$ to $52.2 \%$ \\
Do you want sexual dysfunction treatment? & 33 & 16 & 48.5 & $30.8 \%$ to $66.5 \%$ \\
\hline
\end{tabular}




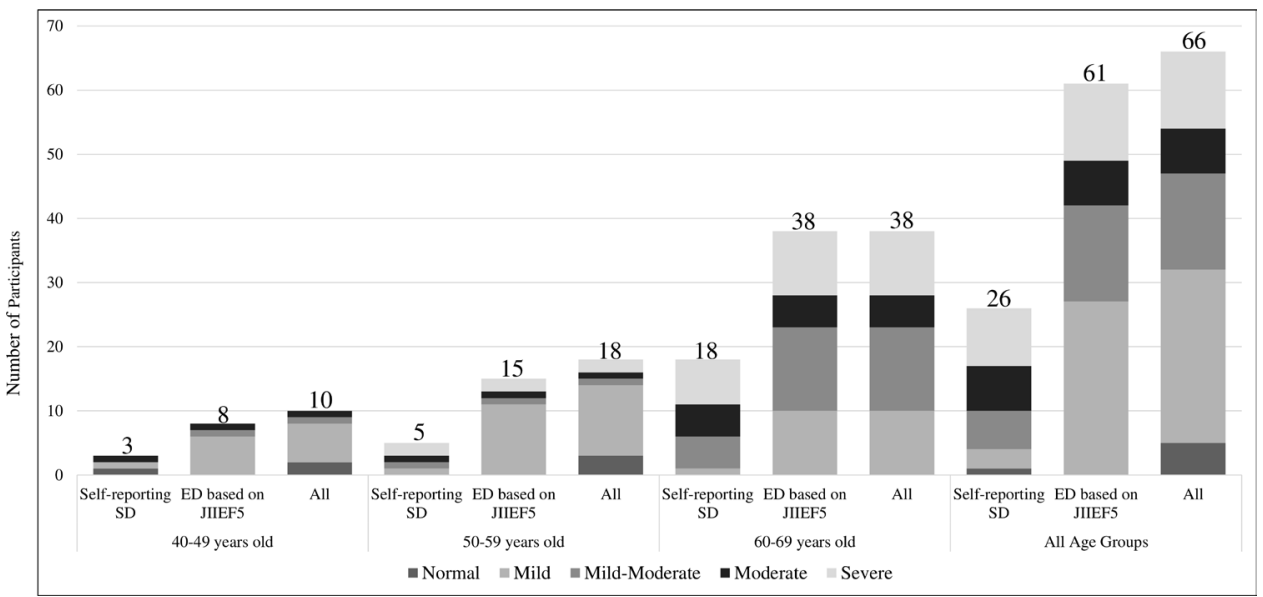

Figure 1 ED distribution among males in a primary care clinic based on comparison of self-reported and objective measures of ED according to age groups and severity $(n=66)$. ED, erectile dysfunction; JIIEF5, Japanese translation of the five-item version of the International Index of Erectile Function (IIEF-5); SD, sexual dysfunction.

lower than the scores in other groups $(40 \mathrm{~s}: 60 \mathrm{~s}, \mathrm{p}=0.01$. $50 \mathrm{~s}: 60 \mathrm{~s}, \mathrm{p}<0.01)$. There was no significant difference between 40-49year-old group and 50-59year-old group $(p=1)$. IIEF-5 scores of participants self-reporting sexual dysfunction had significantly lower IIEF-5 scores than the no self-reported sexual dysfunction group. However, variations in responses by self-report and on the objective IIEF-5 instrument as shown in figure 1 suggests ED severity was not the only factor contributing to awareness of their sexual dysfunction.

\section{Desire for treatment}

Tables 2 and 4 illustrate participants' responses to the inquiries about their views regarding ED. Of respondents, $48 \%(16 / 33)$ desired treatment (table 2$)$. Of the participants indicating a desire for treatment, $75 \%(12 / 16)$ desired treatment by their PCPs, but only one participant had discussed sexual dysfunction with his PCP (table 4).

\section{Barriers for men desiring treatment}

Figure 2 depicts the reasons provided by the subset of men who indicated they would like treatment from their PCPs. The most important barrier was feeling ashamed as reported by seven respondents. The second and third most common reasons given both related to knowledge about availability of treatment, lack of awareness that PCPs can provide treatment and lack of awareness about the availability of treatment. None of the participants chose the physician being a female as a barrier.

\section{Men's perspectives about the desirability of treatment}

Qualitative results

We identified six themes about participants' perspectives on sexual dysfunction from their written comments. Themes included considering sexual dysfunction as normal ageing, attributing sexual dysfunction to decreased libido, importance of sexual activity for a healthy life, good rapport with PCPs, lack of knowledge about treatment and lack of intimate relationship with partner.

\section{Considering sexual dysfunction as normal ageing}

Several men shared their belief that sexual dysfunction is a normal part of ageing. For example, a male in his late sixties said, 'Sexual problem is just caused by normal ageing'. Another male in his late 60s noted, 'I consider sexual problem as ageing. A male in his early 50 s fatalistically concluded, 'It can't be helped because it's ageing'. These perceptions prevented them from considering sexual dysfunction as a medical problem and unawareness based on a belief that 'there was no treatment option for sexual problem?.

Table 3 International Index of Erectile Function-5 scores in each age group

\begin{tabular}{|c|c|c|c|c|c|c|c|c|c|c|c|}
\hline \multirow{2}{*}{$\begin{array}{l}\text { Age group, } \\
\text { years }\end{array}$} & \multicolumn{3}{|l|}{ All } & \multicolumn{3}{|c|}{$\begin{array}{l}\text { Self-reporting sexual } \\
\text { dysfunction (Group A) }\end{array}$} & \multicolumn{3}{|c|}{$\begin{array}{l}\text { No self-reporting sexual } \\
\text { dysfunction (Group B) }\end{array}$} & \multirow{2}{*}{$\begin{array}{l}\text { Mean } \\
\text { difference } \\
\text { (Group A- } \\
\text { Group B) }\end{array}$} & \multirow{2}{*}{$\begin{array}{l}\text { P value } \\
(A, B)\end{array}$} \\
\hline & $\mathbf{n}$ & Mean & SD & $\mathbf{n}$ & Mean & SD & $\mathbf{n}$ & Mean & SD & & \\
\hline $40-49$ & 10 & 18.1 & 3.6 & 3 & 17.0 & 6.6 & 7 & 18.6 & 2.1 & -1.6 & 1 \\
\hline $50-59$ & 18 & 17.1 & 5.1 & 5 & 11.0 & 5.2 & 13 & 19.6 & 1.8 & -8.6 & 0.003 \\
\hline 60-69 & 38 & 11.9 & 6.2 & 18 & 8.8 & 4.6 & 20 & 14.8 & 6.0 & -6.0 & 0.001 \\
\hline
\end{tabular}


Table 4 Response rate among participants who desired sexual dysfunction treatment

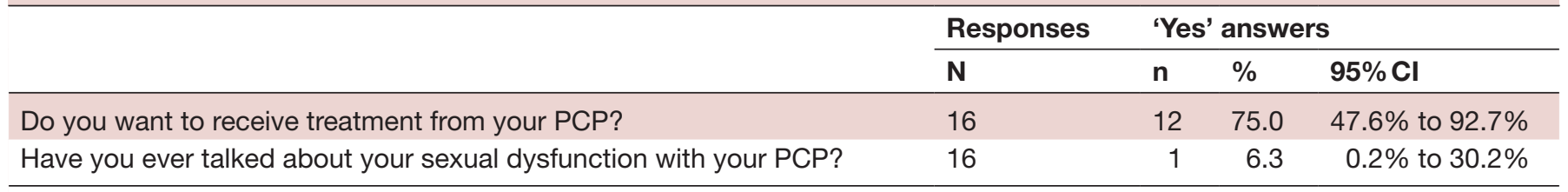

PCP, primary care physician.

\section{Attributing sexual dysfunction to decreased libido}

Some patients considered sexual dysfunction in context of decreasing libido. For example, a male in his mid-50s surmised his sexual dysfunction as thus, 'I have sexual problem, but I think it is due to decreased libido'. A man in his late 60s recounted, 'My libido has been decreasing as I became older'. A man in his mid-60s confided, 'I have become reluctant to have sex with females'. A male in his late 60s stated, 'I don't need treatment because I have graduated from sexual activities'.

\section{Importance of sexual activity for healthy life}

For some men, sexual activity was perceived as important for a healthy life and could be a form of motivation for treatment. Several responses from participants who were interested in sexual dysfunction illustrate this point. A man in his late 60s emphasised, 'I want to have a vigorous life to keep myself healthy'. A man in his mid-60s pointed out, 'I want to become younger by treatment for sexual dysfunction'. A man in his mid-40s lamented, 'I have lost confidence due to my sexual problem'.

\section{Good rapport with primary care physicians}

The comments from participants indicate their trust in their PCPs. For example, a man in his late 50s shared, 'My doctor understands my condition and situation well. A man in his early 50s confided, 'I trust my doctor because I see him regularly'. Another man in his late 50s reported, 'I want treatment because my doctor is a good doctor'. These comments suggest that having good rapport with their PCPs can make them comfortable to discuss issues that may be conceived as shameful such as sexual dysfunction.

\section{Lack of knowledge about treatment}

Lack of knowledge about sexual dysfunction as a medically treatable condition affected some patient's attitudes towards sexual dysfunction treatment. For example, a man in his mid-60s indicated, 'I didn't know sexual problems are treatable'. A male in his early $60 \mathrm{~s}$ responded, 'I want treatment for sexual problem if it is treatable'. A male in his late 50s disclosed, 'I had no idea that sexual problem is medical problem'. These examples demonstrate that there are men who felt that if they had been knowledgeable about sexual dysfunction as a treatable medical condition, that they would have like to be treated.

\section{Lack of intimate relationship with partner}

Some patients attributed apathy about their sexual dysfunction treatment due to the lack of an intimate relationships with their partners. A male in his late 60s conveyed, 'My wife hates having sex and even talking about sex'. Another man in his late 60s confided, 'I and my wife sleep in different rooms. We have not had sex for 35 years'. A man in his early 60s wrote, 'I have been sexless with my wife for a long time'. The lack of an intimate relationship with a partner not surprisingly negatively affected the patients' desire for treatment.

\section{Integration of the mixed data findings}

The intent of merging the survey and qualitative findings was to obtain an enhanced understanding of the findings. Joint display analysis facilitated that process. Figure 3 is the resulting mixed methods joint display figure. It presents an integrated mixed methods model of the factors and mechanisms affecting ED treatment in primary care

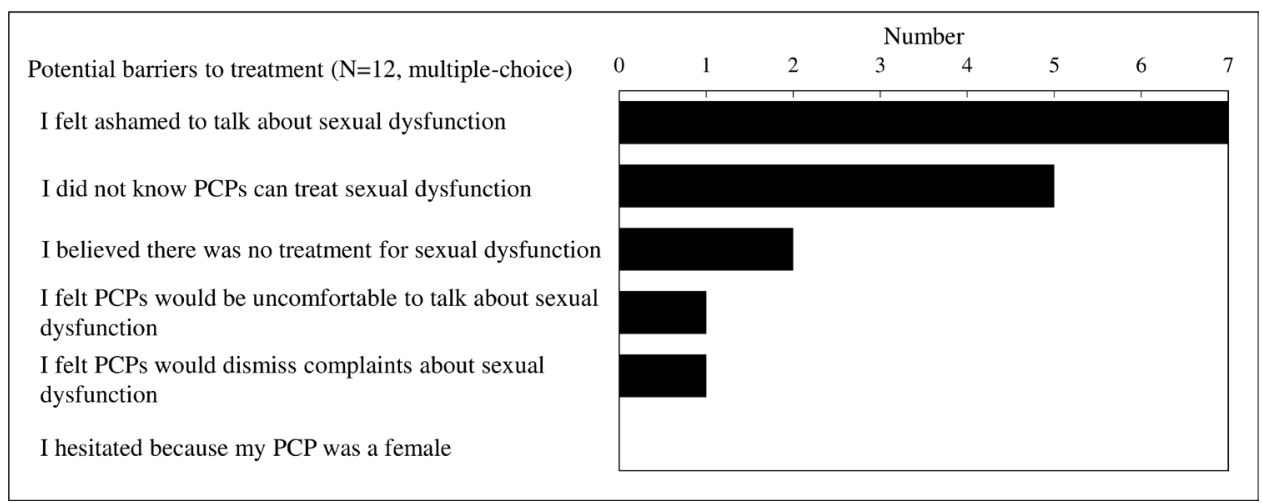

Figure 2 Barriers to seeking treatment for sexual dysfunction reported by participants who indicated they would like treatment from their PCP. PCPs, primary care physicians, PCP, primary care physician. 


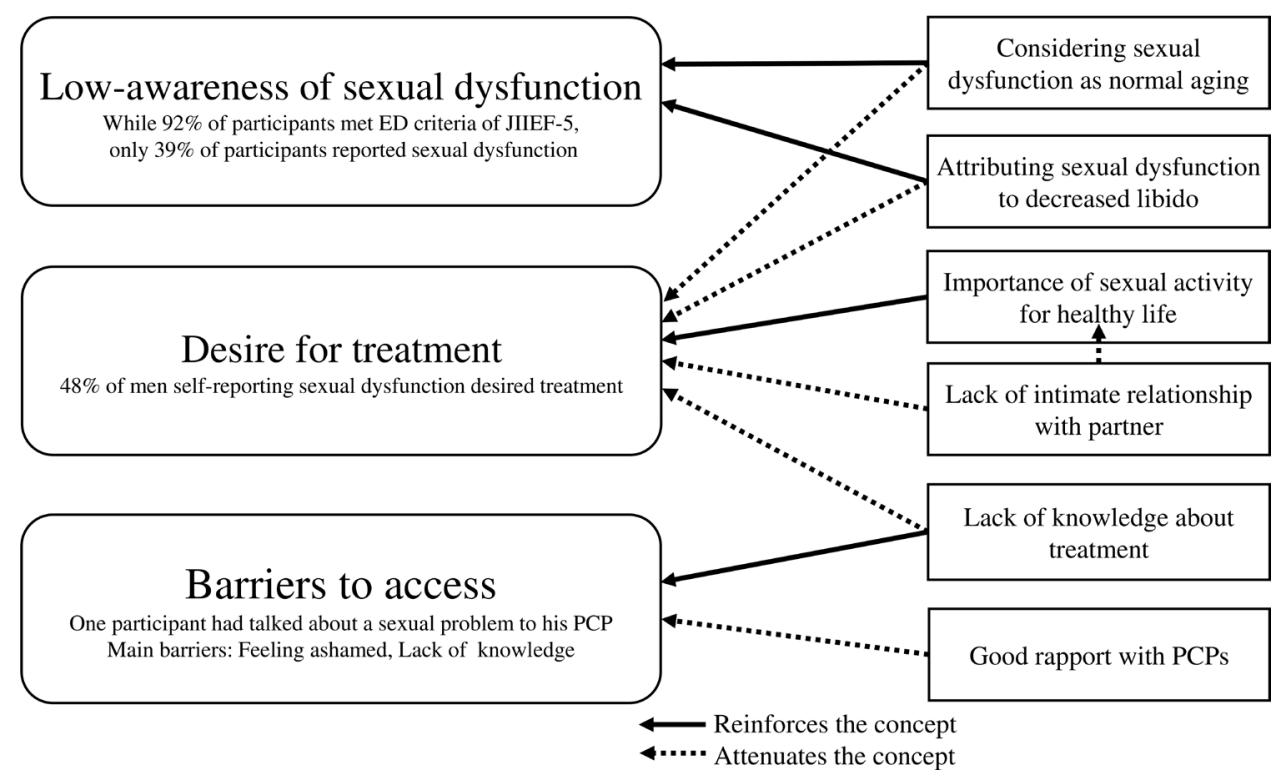

Figure 3 Factors and mechanisms affecting ED treatment in primary care. ED, erectile dysfunction; JIIEF5, Japanese translation of the 5-item version of the International Index of Erectile Function; PCPs, primary care physicians.

that was developed by merging the quantitative survey results and qualitative themes. The quantitative findings showed 'low-awareness of sexual dysfunction'. The themes of 'considering sexual dysfunction as normal ageing' and 'attributing sexual dysfunction to decreased libido' inhibits patients from viewing their sexual dysfunction as a medical condition. Patients with these misconceptions may not seek treatment because they do not consider sexual dysfunction as treatable. In contrast, the theme 'importance of sexual activity for healthy life' serves as motivation for patients to treat their sexual dysfunction. Importantly, a 'lack of intimate relationship with partner' may diminish men's consideration of the 'importance of sexual activity for healthy life' and attenuate their desire for treatment. From quantitative survey results, the main barriers to access were 'feeling ashamed' and 'lack of knowledge'. 'Good rapport with PCPs' can help patients confide with their doctors sensitive topics such as sexual dysfunction, and it could lead patients to receive treatment, a point reinforced by concordance with the qualitative findings. 'Lack of knowledge about treatment' can preclude opportunities to access treatment. This integration of the two types of findings for an overall interpretation, so called metainferences, ${ }^{30}$ revealed concordance in how the two types of data fit, confirmed the findings and supported the conclusions as being robust.

\section{DISCUSSION}

As hypothesised, we identified a gap between selfreported sexual dysfunction and an objective measure of ED. These data suggest that some patients are unaware or do not acknowledge their sexual dysfunction. Findings from the qualitative analysis suggest that some patients may consider sexual dysfunction as normal ageing, or attribute it to decreased libido. While the causes of sexual dysfunction are multifactorial, there are nonetheless misconceptions that appear attributable to a lack of knowledge about sexual dysfunction. An East Asian societal stereotype of the 'asexual older person' ${ }^{\text {, }}$ may have led men to consider sexual dysfunction as a normal process of ageing. In fact, some participants resignedly shared their perspectives about sexual problems. From a clinical perspective, providing correct information is necessary to empower men to optimise their sexual health in primary care.

Embarrassment was found to be the most frequent barrier to consultations among these men. Existing literature supports, particularly in East Asian countries, men feeling ashamed about seeking treatment for sexual dysfunction treatment and it poses a considerable barrier for men seeking treatment. ${ }^{16171920}$ Western studies have found feeling ashamed to be a much less frequent reason than East Asian countries. ${ }^{1415}$ East Asian societal perceptions that sexual activities are not important for older people may reinforce feeling ashamed and reluctance to seek treatment. ${ }^{19}$ The qualitative findings suggest good rapport with men's PCPs may help them overcome this barrier. A previous qualitative study conducted in China also showed fostering good rapport was important to improve access to treatment. ${ }^{19}$

In the qualitative comments, some participants emphasised the importance of sexual activities as contributing to a healthy life. Previous research from China showed having a sexual problem was significantly associated with lower overall life satisfaction and that sexual satisfaction was also significantly associated with better overall life satisfaction and QOL. ${ }^{33}$ The findings of our research suggest sexual activity is also an important factor of healthy life 
for some Japanese men, and it may be a source of motivation for them to seek treatment. On the other hand, some participants mentioned the lack of an intimate relationship with a partner, a factor that would inhibit seeking treatment. Lack of emotional intimacy itself can cause sexual dysfunction. ${ }^{34}$ Clinically, it will be prudent for PCPs to assess the presence and nature of relationships with partners for patients with sexual dysfunction.

While a previous study conducted in China identified male preference for same gender PCPs, ${ }^{19}$ no patients in this study volunteered having a female physician as a barrier. The female PCPs in this study, modern-trained family physicians, may have built good rapport with their patients through good communication skills and thus removed any concern about any gender differences. The possibility that men were too embarrassed to report concern about having a female provided cannot be excluded.

In this study, only one patient volunteered as he had discussed sexual dysfunction with his PCP. Previous research showed the percentages of patients with sexual dysfunction who had talked with their PCPs were $11 \%$ in China, 9\% in Japan and 3\% in South Korea. Reported reasons for not consulting PCPs were lack of perception of a problem, the belief that sexual dysfunction is not a medical issue or embarrassment. A problem with access to medical care was also a main barrier in China. ${ }^{17}$ Although a small sample, in this research, lack of awareness that PCPs can provide treatment was the second most frequent barrier following by embarrassment. Conceivably, patients' perspectives about the role of PCPs may be different between China and Japan. Patients in China viewed PCPs as the most appropriate professional with whom to discuss sexual problem, though some patients were unaware of any other sources of help. ${ }^{19}$ Meanwhile, many patients in Japan may be unaware that PCPs can treat sexual dysfunction. As general medicine/family medicine has been recognised officially as a specialty only in 2017, patients may not know the breadth of care their general medicine/family physician can provide in Japan. For many decades back to the 1950s, an emphasis on subspecialisation in the healthcare system $^{35}$ has compelled patients to see subspecialists for even common problems. This historical context may continue to impel them to believe care for sexual dysfunction should be within the purview of urology even though modern family physicians are trained in the common problems of men's health including the medical and psychosocial aspects of treatment for sexual dysfunction.

In the population of men between the ages of 40 and 69 , there may be as many as 19 million men with ED in Japan, and about 11 million men who are unaware of being afflicted with sexual dysfunction and that treatment is available and should they desire it. ${ }^{46}$ For such a common problem, there is insufficient urologist capacity to see all eligible men. It naturally follows that ED treatment must fall within the scope of PCPs. Patients have far more visits with PCPs than urologists, and PCPs serve as the first contact of care for general medical problems. They are in the position to provide access to treatment to the very large number of men afflicted with ED that they encounter. The training of the modern family physician also to recognise and treat many psychosocial problems, including those associated with sexual dysfunction, further emphasises the potential and value of PCPs elucidating a history of sexual dysfunction and offering treatment to men who desire it. These findings thus suggest that development of systematic approaches to identifying men at risk, increasing awareness about ED, addressing misperceptions and fostering good rapport are important needs in the primary care setting.

A mixed methods approach in this study is evidenced by the use of pragmatism as the worldview guiding the work. ${ }^{23}$ The mixed methods study rationale was to merge attitudinal findings with perspectives on treatment ${ }^{37}$ and obtain an enhanced understanding. ${ }^{27}$ Joint display analysis and presentation were used to facilitate drawing of overall interpretations or metainferences about the study. ${ }^{38}$ Consideration of both types of findings provided a more nuanced perspective on primary study domains of awareness of ED, desire for treatment and barriers to treatment. An integrated rhetorical approach was followed through explanation of the findings in the text. ${ }^{39}$

This research provides a methodological contribution to the literature through the use of a mixed methods joint display figure that integrates the quantitative and qualitative findings. ${ }^{40} 41$ This approach provides an alternative to the use of a table as a joint display. While Bustamante has published a highly elaborate example of joint displays as figure, ${ }^{42}$ there remains relatively few joint display figure examples in the literature. One challenge with a mixed methods joint display figure is the difficulty of including direct metainferences in the joint display figure. In the current study, we have addressed this by drawing metainferences and addressing fit through discussion in the text.

\section{Limitations}

This research was conducted with a small sample size in a single family medicine multiphysician centre. An important risk of selection bias could be that men with the greatest interest in sexual health may have been the most inclined to volunteer to participate in this research. As physicians in the clinic recruited in the midst of patient care in a busy clinic, the sample was not systematically collected and this could also have introduced selection bias. Thus, precaution is necessary in interpreting generalisability and representativeness, especially relative to the proportions and prevalence of attitudes. Importantly, the study was not designed to assess the prevalence of the ED and the proportion of men who want treatment more broadly. However, we do believe the issues identified transfer to the reality of the primary care setting. ${ }^{43}$ While we cannot suggest from these data how many men would desire treatment, we believe these issues to be real and the findings to accurately represent the attitudes and circumstances of the men who participated. Additionally, 
qualitative data collected through open responses do not have the richness and depth of other primary qualitative data collection strategies. While this choice of data collection was made based on feasibility considerations, it may limit interpretations regarding credibility and confirmability of the findings. The authors did not engage in an advanced reflexivity process, though the mixed methods findings suggest the conclusions are nonetheless robust. Prescribing medication for ED is only one strategy of many treatment approaches to address the multifaceted challenge of sexual dysfunction. ${ }^{44}$ Future research could further elucidate the reasons underlying the gap between self-reporting and the objective measure of sexual dysfunction, and lead to a better understanding of patients' perspectives about the impact of sexual dysfunction on their lives.

\section{CONCLUSION}

In this Japanese primary care setting, while the vast majority of male patients met ED criteria on the 5-item version of the International Index of Erectile Function for sexual dysfunction, many did not self-report having sexual dysfunction. Clinicians may need to reframe questioning about specifics rather than use a more general question. From the qualitative analysis, some patients were found to consider sexual dysfunction as normal ageing or attribute it to decreased libido. A mixed methods analysis delineated how patients' misconceptions about sexual dysfunction can lead to low awareness on sexual dysfunction and pose a barrier to access treatment. We conclude PCPs should routinely inquire about sexual dysfunction to facilitate recognition and treatment to improve men's health in Japanese primary care.

Acknowledgements The authors express with great gratitude to Dr Mariko Shimazu and Ms Rania Ajilat for their assistance with this research. We would like to thank the members of Teine Family Medicine Clinic for their hospitality during this research study, where the main results of this paper were obtained.

Contributors YT, RO contributed to the concept of the study. YT, RO, HK and MDF contributed to the analysis and interpretation of the data. YT and MDF contributed to the drafting of the manuscript. All authors contributed to the critical revision of the manuscript and approved the final version for publication and took responsibility for the accuracy and integrity of the study.

Funding MDF participation in this research was made possible through his work in the Mixed Methods Program supported by the Department of Family Medicine, University of Michigan.

Competing interests None declared.

Patient consent for publication Not required.

Ethics approval This study was approved by a research ethics committee of Teine Keijinkai Hospital (ID 2018-166).

Provenance and peer review Not commissioned; externally peer reviewed.

Data availability statement Data are available upon reasonable request. Deidentified data are available through the corresponding author.

Supplemental material This content has been supplied by the author(s). It has not been vetted by BMJ Publishing Group Limited (BMJ) and may not have been peer-reviewed. Any opinions or recommendations discussed are solely those of the author(s) and are not endorsed by BMJ. BMJ disclaims all liability and responsibility arising from any reliance placed on the content. Where the content includes any translated material, BMJ does not warrant the accuracy and reliability of the translations (including but not limited to local regulations, clinical guidelines, terminology, drug names and drug dosages), and is not responsible for any error and/or omissions arising from translation and adaptation or otherwise.

Open access This is an open access article distributed in accordance with the Creative Commons Attribution Non Commercial (CC BY-NC 4.0) license, which permits others to distribute, remix, adapt, build upon this work non-commercially, and license their derivative works on different terms, provided the original work is properly cited, appropriate credit is given, any changes made indicated, and the use is non-commercial. See: http://creativecommons.org/licenses/by-nc/4.0/.

ORCID iD

Yuki Takeuchi http://orcid.org/0000-0003-4095-0230

\section{REFERENCES}

1 American Psychiatric Association. Sexual dysfunctions. DSM library. Available: https://dsm.psychiatryonline.org/doi/10.1176/appi.books. 9780890425596.dsm13 [Accessed 14 Nov 2019].

2 Shamloul R, Ghanem H. Erectile dysfunction. Lancet 2013;381:153-65.

3 Goldstein I, Goren A, Li VW, et al. Epidemiology update of erectile dysfunction in eight countries with high burden. Sex Med Rev 2020;8:48-58.

4 Cheng JYW, Ng EML, Chen RYL, et al. Prevalence of erectile dysfunction in Asian populations: a meta-analysis. Int J Impot Res 2007;19:229-44.

5 Grover SA, Lowensteyn I, Kaouache M, et al. The prevalence of erectile dysfunction in the primary care setting. Arch Intern Med 2006;166:213.

6 Kushiro T, Takahashi A, Saito F, et al. Erectile dysfunction and its influence on quality of life in patients with essential hypertension. Am J Hyperten 2005;18:427-30.

7 Nieschlag E, Nieschlag S. Endocrine history: the history of discovery, synthesis and development of testosterone for clinical use. Eur $J$ Endocrinol 2019;180:R201-12.

8 Donatucci C, Cui Z, Fang Y, et al. Long-Term treatment patterns of testosterone replacement medications. J Sex Med 2014;11:2092-9.

9 FDA. Drug safety communication: FDA cautions about using testosterone products for low testosterone due to aging. Available: https://www.fda.gov/drugs/drug-safety-and-availability/fda-drugsafety-communication-fda-cautions-about-using-testosteroneproducts-low-testosterone-due [Accessed $15 \mathrm{Feb} 2020]$.

10 Ministry of Health, Labour and Welfare. "Yakuzai Bunrui Joho Etsuran System"(Medicines Information data base). Available: https:// shinryohoshu.mhlw.go.jp/shinryohoshu/yakuzaiMenu/ [Accessed 12 May 2020].

11 Huang SA, Lie JD. Phosphodiesterase-5 (PDE5) inhibitors in the management of erectile dysfunction. P T 2013;38:407-19.

12 Wessells $\mathrm{H}$, Joyce GF, Wise M, et al. Erectile dysfunction. J Urol 2007;177:1675-81.

13 Zion Market Research. Global erectile dysfunction drugs market will reach USD 7.10 billion by, 2024. Available: https://www. globenewswire.com/news-release/2018/10/05/1617442/0/en/GlobalErectile-Dysfunction-Drugs-Market-Will-Reach-USD-7-10-Billion-by2024-Zion-Market-Research.html [Accessed 12 Dec 2019].

14 Laumann EO, Glasser DB, Neves RCS, et al. A population-based survey of sexual activity, sexual problems and associated helpseeking behavior patterns in mature adults in the United States of America. Int J Impot Res 2009;21:171-8.

15 Buvat J, Glasser D, Neves RCS, et al. Sexual problems and associated help-seeking behavior patterns: results of a populationbased survey in France. Int $J$ Urol 2009;16:632-8.

16 Zhang K, Yu W, He Z-J, et al. Help-Seeking behavior for erectile dysfunction: a clinic-based survey in China. Asian J Androl 2014;16:131-5.

17 Nicolosi A, Glasser DB, Kim SC, et al. Sexual behaviour and dysfunction and help-seeking patterns in adults aged $40-80$ years in the urban population of Asian countries. BJU Int 2005;95:609-14.

18 Marwick C. Survey says patients expect little physician help on sex. JAMA 1999;281:2173-4.

19 Gott M, Hinchliff S. Barriers to seeking treatment for sexual problems in primary care: a qualitative study with older people. Fam Pract 2003;20:690-5.

20 Moreira ED, Kim S-C, Glasser D, et al. Sexual activity, prevalence of sexual problems, and associated help-seeking patterns in men and women aged 40-80 years in Korea: data from the global study of sexual attitudes and behaviors (GSSAB). J Sex Med 2006;3:201-11. 
21 Shultz CG, Chu MS, Yajima A, et al. The cultural context of teaching and learning sexual health care examinations in Japan: a mixed methods case study assessing the use of standardized patient instructors among Japanese family physician trainees of the Shizuoka family medicine program. Asia Pac Fam Med 2015;14:1-11.

22 Creswell JW, Hirose M. Mixed methods and survey research in family medicine and community health. Fam Med Community Health 2019;7:e000086.

23 Morgan DL. Pragmatism as a paradigm for social research. Qual Inq 2014;20:1045-53.

24 Ishida M, Araki C. "Chukonen tanshinsha no sexuality. Haigusya ga iru chukonen tono hikakukento" (Sexuality in middle and old aged people Conparison between married and unmarried people). Jpn J Sexology 2005;23:56-70.

25 Kimoto Y. The new Japanese versions of Internatinal index of Eretile function (IIEF) and IIEF5. Japanese J Impot Res 2009;24:295-303.

26 Rosen RC, Cappelleri JC, Smith MD, et al. Development and evaluation of an abridged, 5-item version of the International index of erectile function (IIEF-5) as a diagnostic tool for erectile dysfunction. Int J Impot Res 1999;11:319-26.

27 Fetters MD. Identifying the intent of integration and illustrating features in mixed methods procedural diagrams. In: Fetters MD, ed. The mixed methods research Workbook-Activities for designing, conducting, and publishing projects. Thousand Oaks, CA: Sage, Inc, 2020.

28 Crabtree BF, Miller WL. Doing qualitative research. 2nd edn. Thousand Oaks, CA: SAGE Publications, 1999.

29 Miller WL, Crabtree BF. The dance of interpretation. In: Crabtree BF, Miller WL, eds. Doing qualitative research. 2nd edn. Thousand Oaks, CA: Sage, 1999: 127-43.

30 Fetters MD. Chapter 14. Developing a Joint Display. In: Fetters MD, ed. The mixed methods research workbook. Thousand Oaks, CA: SAGE Publications, 2020: 193-210.

31 Fetters MD, Curry LA, Creswell JW. Achieving integration in mixed methods designs-principles and practices. Health Serv Res 2013;48:2134-56.

32 Fetters MD. Chapter 13. Performing Fundamental Steps in Mixed Methods Data Analysis. In: Fetters MD, ed. The mixed methods research workbook. Thousand Oaks, CA: SAGE Publications, 2020: 175-92.
33 Lau JTF, Kim JH, Tsui H-Y. Prevalence of male and female sexual problems, perceptions related to sex and association with quality of life in a Chinese population: a population-based study. Int J Impot Res 2005;17:494-505.

34 Pascoal PM, Narciso I, Pereira NM. Emotional intimacy is the best predictor of sexual satisfaction of men and women with sexual arousal problems. Int J Impot Res 2013;25:51-5.

35 Fetters MD, Yokoyama I. Medical education in Japan. In: Babb JD, ed. The SAGE Handbook of modern Japanese studies. London, UK: SAGE Publications, 2014: 299-319.

36 Statistics bureau M of la and C. Stastistics Bureau of Japan. Available: https://www.stat.go.jp/english/data/jinsui/tsuki/index.html [Accessed 14 Nov 2019].

37 Fetters MD. Identifying a topic, rationale, and potential feasibility issues for conducting a mixed methods research or evaluation project. In: Fetters MD, ed. The mixed methods research WorkbookActivities for designing, conducting, and publishing projects. Thousand Oaks, CA: Sage, Inc, 2020.

38 Fetters MD. Developing a joint display. In: Fetters MD, ed. The mixed methods research Workbook-Activities for designing, conducting, and publishing projects. Thousand Oaks, CA: Sage, Inc, 2020.

39 Fetters MD, Molina-Azorin JF. The Journal of Mixed Methods Research Starts a New Decade: The Mixed Methods Research Integration Trilogy and Its Dimensions. J Mix Methods Res 2017;11:291-307.

40 Fetters MD. Chapter 14. Developing a Joint display. In: Fetters MD, ed. The mixed methods research workbook. Thousand Oaks, CA: SAGE Publications, 2020: 193-210.

41 Guetterman TC, Fetters MD, Creswell JW. Integrating quantitative and qualitative results in health science mixed methods research through joint displays. Ann Fam Med 2015;13:554-61.

42 Bustamante C. TPACK and teachers of Spanish: development of a Theory-Based joint display in a mixed methods research case study. J Mix Methods Res 2019;13:163-78 https://doi.org/

43 Fetters MD. Chapter 9. Intergrating through sampling in mixed methods research. In: Fetters MD, ed. The mixed methods research workbook. Thousand Oaks, CA: SAGE Publications, 2020: 105-21.

44 Stridh A, Pontén M, Arver S, et al. Placebo responses among men with erectile dysfunction enrolled in phosphodiesterase 5 inhibitor trials: a systematic review and meta-analysis. JAMA Netw Open 2020;3:e201423. 